The precise mode of the formation of form-aldehyde in the process of assimilation is a matter of dispute. But it is quite clear that either the carbon dioxide or the water, which are the materials from which it is formed, must suffer dissociation. And this requires a supply of energy to accomplish it. Warington has drawn attention to the striking fact that in the case of the nitrifying bacterium, assimilation may go on without the intervention of chlorophyll, the energy being supplied by the oxidation of ammonia. This brings us down to the fact, which has long been suspected, that protoplasm is at the bottom of the whole business, and that chlorophyll only plays some subsidiary and indirect part, perhaps, as Adolph Baeyer long ago suggested, of temporarily tixing carbon oxide like hæmoglobin, and so facilitating the dissociation.

Chlorophyll itself is still the subject of the careful study by Dr. Schunck, originally commenced by him some years ago at Kew. This will, I hope, give us eventually an accurate insight into the chemical constitution of this important substance.

The steps in plant metabolism which follow the synthesis of the proto-carbohydrate are still obscure. Brown and Morris have arrived at the unexpected conclusion that "cane-sugar is the first sugar to be synthesised by the assimilatory processes." I made some remarks upon this at the time (Joum. Chem. Soc., I893, 673), which I may be permitted to reproduce here.

"The point of view arrived at by botanists was briefly stated by Sachs in the case of the sugar-beet, starch in the leaf, glucose in the petiole, cane-sugar in the root. The facts in the sugar-cane seem to be strictly comparable (Kew Bulletin, I891, 35-4I). Cane-sugar the botanist looks on, therefore, as a 'reserve material.' We may call 'glucose ' the sugar 'currency' of the plant, cane-sugar its 'banking reserve.'

"The immediate result of the diastatic transformation of starch is not glucose, but maltose. But Mr. Horace Brown has shown in his remarkable experiments on feeding barley embryos that, while they can readily convert maltose into cane-sugar, they altogether fail to do this with glucose. We may conclude, therefore, that glucose is, from the point of view of vegetable nutrition, a somewhat inert body. On the other hand, evidence is apparently wanting that maltose plays the part in vegetable metabolism that might be expected of it. Its conversion into glucose may be perhaps accounted for by the constant presence in plant tissues of vegetable acids. But, so far, the change would seem to be positively disadvantagecus. Perhaps glucose, in the botanical sense, will prove to have a not very exact chenical connotation.

"That the connection between cane-sugar and starch is intimate is a conclusion to which both the chemical and the botanical evidence seems to point. And on botanical grounds this would seem to be equally true of its connection with cellulose.

"It must be confessed that the conclusion that "cane-sugar" is the first sugar to be synthesised by the assimilatory processe seems hard to reconcile with its probable high chemical complexity, and with the fact that, botanically, it seems to stand at the end and not at the beginning of the series of metabolic change."

\section{Protoplasmic Chemistry.}

The synthesis of proteids is the problem which is second only in importance to that of carbohydrates. Loew's views of this deserve attentive study. Asparagin, as has long been suspected, plays an important part. It has, he says, two sources in the plant. "It may either be formed diréctly from glucose, ammonia (or nitrates) and sulphatcs, or it may be a transitory product between protein-decomposition and reconstruction from the fragments" (10c. cit., 64).

In the remarks I made to the Chemical Society I ventured to express my conviction that the chemical processes which took place under the influence of protoplasm were probably of a different kind from those with which the chemist is ordinarily occupied. The plant produces a profusion of substances, apparently with great facility, which the chemist can only build up in the most circuitous way. As Victor Meyer (Pharm. Journ., I 890,773 ' has remarked: "In order to isolate an organic substance we are generally confined to the purely accidental properties of crystallisation and volatilisation." In other words, the chemist only deals with bcdies of great molecular stability ; while it can not be doubted that those which play a part in the processes of life are the very opposite in every respect. I am convinced that if the chemist is to help in the field of protoplasmic activity he will have to transcend his present limitations, and be prepared to admit that as there may be more than one algebra, there may be more than one chemistry. I am glad to see that a somewhat similar idea has been suggested by other fields of inquiry. Prof. Meldola (NATURE, xlii. 250) thinks that the investigation of photochemical processes "may lead to the recognition of a new order of chemical attraction, or of the old chemical attrac. tion in a different degree." I am delighted to see that the ideas which were floating, I confess, in a very nebulous form in my brain are being clothed with greater precision by Loew.

In the paper which I have already quoted, he says of proteids (loc. cit., I3): "They are exceedingly labile compounds that can be easily converted into relatively stable ones. A great lability is the indispensable and necessary foundation for the production of the various actions of the living protoplasm, for the mode of motions that move the life-machinery. There is a source of motion in the labile position of atoms in molecules, a source that has hitherto not been taken into consideration either by chemists or by physicists."

But I must say no more. The problems to which I might invite attention on an occasion like this are endless. I have not even attempted to do justice to the work that has been accom. plished amongst ourselves, full of interest and novelty as it is. But I will venture to say this, that if capacity and earnestness afford an augury of success, the prospects of the future of our Section possess every element of promise.

\section{PHYSICS AT THE BRITISH ASSOCIATION.}

$\mathrm{THE}$, proceedings of this Section were commenced by the delivery of the presidential address by Prof. W. M. Hicks. In seconding the vote of thanks to the President, Prof. Fitz. gerald referred to the possible change of mass with temperature, suggested in the address, and pointed out that such a phenomenon would show itself by a deviation of planetary motions from strict conformity to Kepler's laws, owing to their change of mass on cooling.

Sir Douglas Galton exhibited plans of the German Reichsanstalt, and of the new buildings in course of construction, and gave a more detailed account of the management of this institution than is contained in his presidential address to the Association. Ilis object in reading the paper was to revive a movement set on foot at a previous meeting by Prof. Oliver Lodge. The Committee appointed at that time to consider the question of a National Physical Laboratory for the United Kingdom made but little progress, possibly because they did not propose to develop any existing institution. He suggested that the scope of the Kew Observatory should be extended so as to include research, and that it be made the starting-point for the national laboratory.

A discussion followed, in which several members took part. Prof. Riicker lamented the want of concentration and organisation in research work, and thought a national laboratory might remedy this. He regretted that the day was passing away when a man could undertake both teaching and research, because, in his opinion, teachers should not give up research. Prof. Oliver Lodge drew attention to the enormous advantages possessed by a national institution, for carrying on researches extending over a long period. In a university laboratory such research would possibly be discontinued with a change of professor. The universities would still do pioneer work, discovering new fields of research and obtaining preliminary results. Prof. Fitzgerald, on the other hand, did not think it advisable to hand over research to a national laboratory, whereas he strongly advocated an extension of the standardising work performed at Kew. He believed that the highest kind of instruction was training in research work, and it was the function of the universities to give this instruction. Instead of that, the professors are called upon to cram old knowledge into immature and stupid students. The Section has appointed a Committee to reconsider the question of a national laboratory.

Prof. Henrici read a paper on the teaching of geometrical drawing in schools, which was, he said, as a rule very bad. He pointed out that Euclid's constructions are generally followed, the use of the set-square being discarded and only straight-edges and compasses used. He urged the desirability of discarding Euclic in the teaching of geometrical drawing, advocating the use of the set-square from the very commencement. The examples ought to be so arranged that a student can verify his constructions for himself; he therefore suggested the appointment of a Committee to report on the whole question and issue 
a syllabus of examples. This suggestion was adopted by the Section.

The range of subjects included in the work of the Section was perhaps nowhere better exemplified than in the passage to the next paper, a report on cosmic dust, by Dr. J. Murray. An examination of the red clay from the bottom of the Pacific Ocean, in places 1000 miles from any coast, enables three classes of magnetic particles to be distinguished; these are-crystalline fragments of magnetic or titanic iron, dark shiny spherules containing metallic iron, and the brownish spherules known as chondres. The various layers of manganese nodules found surrounding nuclei of tertiary teeth or bones contain these black and brown spherules, and there is every indication that the brown ones are of extra-terrestrial origin. In this case they ought to occur at all, or at any rate many, points on the earth's surface ; Dr. Murray has, however, looked for them in vain both in the dust of Greenland glaciers and on the summit of Ben Nevis. $\mathrm{He}$ is of opinion that the accumulation of meteoric dust takes place with exceeding slowness, say about 20 lbs. of dust per square mile per century, and that the bed of the Pacific Ocean has not received one foot of deposit since the tertiary period. Consequently any attempt to gather these particles will probably be fruitless, unless continued over a long period. He wished for suggestions as to the best method of procedure in the future. It was pointed out that a good opportunity for the collection of meteorites will be afforded by the meteor shower of November I 899 .

The Committee on underground temperature have been fortunate this year in obtaining records from a bore-hole in New South Wales, the first observations made in the southern hemisphere. The bore-hole is situated near Port Jackson, close to Syclney Harbour ; it is 2929 feet deep, and contains water. The sadient observed was a small one, being a rise of $x^{\circ} F$. in descending 80 feet vertically. The observers suspected that the temperature of the rock was influenced by the proximity of the water in the harbour, but an examination of the temperature distribution in the harbour did not confirm this. Lord Kelvin suggested the African mines as a new field for observations.

Prof. S. P. Thompson reported the recommendations of the Committee on the size of pages of scientific periodicals. It is considered advisable to retain quarto and octavo sizes, and certain limits for text and margin are given for each of these sizes. There appeared to be a strong feeling against any change in the sizes of the Royal Society's publications. During the year the Committee will endeavour to induce other scientific societies to adopt the standard sizes recommended.

Prof. Ruicker communicated the results of a comparison of magnetic standard instruments, made by himself and Mr. W. Watson. In his presidential address to the Section last year he showed that it was useless to proceed further with a magnetic survey until a direct comparison of standards used in the various observatories had been made, because it was well known that instruments differed greatly. During the year he has visited the various magnetic observatories, carrying a portable declinometer of the Kew pattern, and with Mr. Watson's assistance has directly compared the simultaneous readings of his declinometer and that of the observatory. Errors are found in the latter, which are in every case traceable to magnetic material in or on the wooden box containing the suspended magnet. If this box be replaced by an ebonite one, the error disappears. It is, how ever, easier to allow for the error than to get rid of it; its amount is perfectly definite.

On Friday the Section sat jointly with Section B. Lord Rayleigh read a paper on the refractivity and viscosity of these gases. He described how, by means of an electric arc, kept up for several weeks in a mixture of oxygen and atmospheric nitrogen, he finally obtained more than a litre of argon at atmospheric pressure. This proved to have the same density as the specimen obtained by the magnesium method. The re fractive index was measured by the interference method of Fizeau, the two beams being separated by slits in front of the lens nearest the eyepiece. The latter was constructed of cylindrical lenses. To avoid the use of cross-wires, the tubes containing the gases under comparison were arranged so as not to occupy the whole field of view, some light passing parallel to, and outside them ; two sets of fringes were thus obtained, which could be brought to coincidence by varying the pressure of either gas. Adjustments were made for several pressures, one of the tubes always containing air. The values of the refractivity $(\mu-1)$ were, for argon 0.961 , and for helium $0^{\circ} 146$, that of air being taken as unity. The viscosity of each gas was measured by its rate of flow through a capillary tube, the results being (air $=1$ ) argon I.2I, helium 0.96 . Lord Rayleigh mentioned that a sample of nitrogen collected from a Bath spring, where it bubbles out along with the water, gave the $\mathrm{D}_{3}$ line of helium. Dr. Gladstone showed that the results of these experiments assign to argon the atomic weight 20 , its specific refractive energy being intermediate between those of fluorine and sodium, but not between those of potassium and calcium.

Prof. Schuster then opened a discussion on the evidence to be gathered as to the simple or compound character of a gas from the constitution of its spectrum. Recent spectroscopic work in connection with argon and cleveite gas has directed attention to the double spectra exhibited by these substances, and conjectures have been made that the two spectra indicate the gases to be mixtures. Prof. Schuster expressed strongly the view that gases with double spectra are not necessarily mixtures or compounds. He quoted in support of this th cases of sodium and mercury vapours, and oxygen, in all of which the absorption spectrum differs from that of the luminous vapour. The difficulty is not explained by assuming dissociation to occur, because some substances have three or more spectra. He thought mere examination of spectra would not suffice to determine whether an unknown substance is an element, mixture of elements, or compound.

The despondent view of Prof. Schuster was not shared by Prof. Runge, of Hanover, who at this point contributed an account of the researches of himself and Prof. Paschen on the spectrum of cleveite gas, showing that it is a mixture. (An account of this work by the authors themselves will be found on p. 520.)

Dr. G. J. Stoney contributed to the discussion by a paper on the interpretation of spectra.

On Saturday the Section was subdivided into two departments, mathematics and meteorology.

In the department of mathematics, Lord Kelvin read a paper on the translational and vibrational energies of vibrators after impacts on fixed walls, in which he sought to find an exception to the Maxwell-Boltzmann theorem relating to the average translational energy of the molecules of a gas. He calculated the time-average of the translational energy of a free particle after coming into contact with a vibrating particle, and found it always in excess of that which would be given by the MaxwellBoltzmann law, though approximating more nearly to that average when the number of encounters was considerable; and that it seemed ultimately to give a total average out of accordance with the law. In the discussion which followed, Mr. G. II. Bryan pointed out that the Maxwell-Boltzmann law referred to the statistical average energy of a great number of particles, not to the time-average energy of a single particle.

Prof. Hicks, in his paper on a spherical vortex, stated that he had proved the possibility of building up a compound spherical vortex consisting of successive shells in which the rotation is oppositely directed, the vorticity and size of each shell satisfying a definite relation. In a paper on bicyclic voriex aggregates, he stated that it was possible, with given current and vortex-sheets, to have a steady spiral motion round an axis, compounded of motion in planes through the axis and motion in circles round the axis, the cyclic constants of the two component motions being independent of each other.

Mr. G. T. Walker showed an ingenious top in the shape of a fiattened ellipsoid in which rotation could become converted into oscillations, and vice versá, by means of an adjustable piece which could be arranged unsymmetrically.

Dr. Burton made some suggestions as to matter and gravitation in the cellular vortex ether described in Prof. Hicks's presidential address.

Mr. P. H. Cowell read an important paper on recent developments of the lunar theory, chiefly by Dr. G. W. Hill, extended in the current number. of the American Journal by an admirable paper by Prof. E. W. Brown. The order of work in attacking problems in the lunar theory is quite altered and much simplified in the new method. In a short discussion which followed, $\mathrm{Mr}$. Cowell stated that Prof. Brown was engaged in bringing out a treatise on the lunar theory.

Prof. J. D. Everett read a paper on absolute and relative motion; and Mr. W. H. Everett made a communication on the calculation of the magnetic field due to a current in a solenoid.

In pure mathematics, Major MacMahon gare an interest ing method of graphically representing partitions of numbers.

NO. I 352 , VOL. 52$]$ 
Colonel Cunningham read a paper on Mersenne's numbers, which are numbers of the form $2^{q}-\mathrm{I}$, where $q$ is a prime, and which were first disctssed by Mersenne about the year I664. Colonel Cunningham also described a book of tables which he proposed to calculate, giving the solution of the congruence $2^{x} \equiv \mathrm{R}$ (mod. $p$ ) for all moduli $(p)$ which are primes, or powers of primes, up to 1000 . There are to be two tables for each modulus, one giving the values of $\mathrm{R}$ for a series of values of $x$; and the other giving the smallest values of $x$ for a series of values of $R$. He described some of the uses of such a table, and stated that the plan on which it would be drawn up would be precisely like a somewhat similar table by Jacobi, described in Prof. Cayley's report on mathematical tables in the British Association Report of 1876 .

Prof. Alfred Lodge drew the attention of the Section to a multiplication table up to $1000 \times 1000$, drawn up by Mr. M. B. Cotsworth, of Holdgate, York, which was exhibited ; it is similar to Crelle's table of the same extent, though in some respects more convenient.

Prof. M. J. M. Hill described two species of tetrahedron, the volume of any member of which can be determined without using the proposition that tetrahedrons on equal bases, and having equal altitudes, are equal.

In the department of meteorology, Mr. Eric S. Bruce put forward a new theory of lightning flashes, based on the principle of the pin-hole camera. The light from a concealed flash might, he supposed, pass through a small aperture in the concealing cloud and fall on another cloud, forming an inverted image of the flash. If there were several apertures we should have as many images. They would be faint, possibly too faint to affect a photographic plate. Moreover, if the receiving cloud were of irregular shape, an originally straight flash would appear distorted into a zig-zag line on the cloud. Mr. Symons thought a brighter patch of light ought to occur at the angles of the image thus distorted, and he scarcely thought the conditions imagined by Mr. Bruce corresponded with those of nature.

The report of the Committee on earth tremors was presented by Mr. Symons, who, in referring to the delicacy of the instruments used in their observations, said that an angle equal to that subtended by a chord $\mathbf{I}$ inch long at the centre of a circle Iooo miles in radius could be detected. Since last report two bifilar pendulums have been purchased, of the kind described in NATURE, vol. 1. pp. 246-249 (1894); each possesses its own photographic recording apparatus. One of these has been recently erected in the cellar of Mr. Davison's house in Birming ham; the other should have been placed in a house threequarters of a mile to the east, but this was found impracticable. It will be placed somewhere in the neighbourhood, and comparisons of the records of the instruments will be made during the year, after which the second one will be available for another station. An appendix to the report by Mr. Davison gives the bibliography and classification of horizontal pendulums.

Prof. John Milne gave an account of the long report of the Committee on seismological phenomena in Japan. This commences by a reference to the great loss caused by the recent fire at Prof. Milne's house and observatory, after which follows a description of the records of the Gray-Milne seismograph. Attached to the report is a catalogue of 8331 earthquake shocks recorded in Japan between I 885 and I892, giving full particular: of the centre and area of disturbance. It enables the approximate weight of each to be found, and permits the division of Japan into fifteen distinct seismic districts. The next section of the report deals with the rate of propagation of earthquake disturbances from Japan to Europe. The small tremors which occur in the ten seconds or so before an earthquake shock are transmitted to Europe, but they are spread over half an hour ; it appears, therefore, that the preliminary tremors either travel more quickly, or reach Europe by a shorter route than the main shock. The latter is known to travel along the surface at about 3000 metres per second. Do the tremors travel at 8000 to II, 000 metres per second, or do they pass through the earth, not round it? If the latter, we may hope for some further knowledge concerning the interior of the globe. Prof. Milne has set up horizontal pendulums in nearly a score of places, and finds great differences in their behaviour. They all exhibit a general displacement, i.e. tilt, in the same direction, and similar long-period movements. Examined from hour to hour, however, some of them show the existence of a diurnal wave. After a long and very laborious search, graphically described to the Section by Prof. Milne, he succeeded in tracing this diurnal effect to the local removal of load from the alluvium by greater evaporation from exposed areas. At night the movement is slight, and is probably accounted for by the condensation, at the cold surface, of aqueous vapour after rising through the warm earth. Some observations have been made on the disturbance of the pendulums by earth tremors. Their cause has not been ascertained, but they always occur with greatest intensity between 5 and $9 \mathrm{a} . \mathrm{m}$. They are most marked with a steep barometer gradient and consequent wind, local or distant.

As Prof. Milne has now returned from Japan, and the earth. quake catalogue is completed, the Committees on earth tremors and seismological phenomena have united under the latter name. The new Committee is a large one, and with Prof. Milne and Mr. Davison as joint secretaries, it ought to do good work.

A new theory of thunderstorms was advanced by Prof. Michie Smith in his paper on Indian thunderstorms. His observations, made at Madras, showed that sheet-lightning occurs there every evening during several months of the year, always in the south west and near the horizon. Lightning phenomena in the morning occur, on the other hand, in the north-east. The phenomena consist of actual discharges between two clouds, or two portions of the same cloud, and are not reflections of distant lightning; they take place in the upper portions of low-lying cumulus clouds. Prof. Smith attributes them to the clouds formed in the regions of still air at the meeting of the land and sea breezes, and has observed in these regions the simultaneous rise of two close parallel clouds from the edge of the cumulus such clouds are scarcely distinguishable except with oblique illumination, and it is within, or between, them that the discharges occur. The time of their formation depends on the hour at which the sea breeze sets in, being roughly three hours later. The land breeze being dry and dusty is negatively charged, while the sea breeze is known to carry a strong positive charge; equalisation of the electrical states of the clouds formed out of these will, therefore, give rise to lightning. Prof Smith referred to the iridescence or nacreous appearance of the edges of the clouds when rapidly sinking, and considered this effect to be due to the dust left behind by them.

This paper gave rise to an interesting discussion, chiefly with reference to the origin of dust in clouds, and the source of their electricity. Mr. John Aitken pointed out that thunderstorms are most probably the effect, not the cause, of purifying the air. He gave instances of thunderstorms on several successive days, all of which left the air dusty and impure; eventually the air cleared, and no more thunder occurred. Prof. Schuster alluded to the fact that twenty-five theories of thunderstorms had been put forward in a dozen years, and in a single year five appeared. He attributed the positive charge of the sea breeze to the elec trification of the air by the spray from the breaking waves; Lenard has shown that the spray of pure water gives a negative charge to the air, while that of salt water communicates a positive charge. He believed the dust of clouds to be acquired locally, except that at high altitudes, which we know to be carried long distances. A proof of this is to be found in the Himalayas where certain valleys are dusty and others fairly free from dust, although all receive the wind from the Indian plains. His observations of nacreous clouds in England had led him to connect them rather with the ice particles of cirrus clouds than with dust. To this latter point Prof. Michie Smith replied that the nacreous appearance fits the edge of the cumulus so closely that he believes the two to be connected.

The Committee on the application of photography to meteorology are proceeding with the photography of clouds nea the sun by means of two cameras at a fixed distance apart, and exposed simultaneously by an electrical arrangement. In thi way they hope to obtain absolute measurements of cloud altitudes. For purposes of measurement the sun's image appears in all the photographs. A photograph of the rainbow, by Mr. Andrews of Coventry, is the first of its kind received by the Committee. It shows the secondary bow, and the greater brightness of the region within the bow.

During a recent visit to the Engadine, Prof. Schuster has made observations on the atmospheric electricity near the ground at different heights above sea-level. The readings wer taken with Lord Kelvin's portable electrometer, which worked very satisfactorily and seems well adapted for such purposes. In all cases positive charges were found, increasing with height but in an apparently erratic fashion. The normal positive charge at the foot of a glacier was found to be strengthened by a wind blowing down it, and Lenard's observations on the negative

No. $135^{2}$, VOL. 52$]$ 
electricity of waterfalls were all confirmed. The daily curve of atmospheric potential in the valley of Pontresina shows a maximum at I I a.m., dipping a little and rising again to an afternoon maximum at 5 p.m., then rapidly descending as the evening breeze sets in. Discussion on the paper related chiefly to the behaviour and temperature errors of portable electrometers, the latter being somewhat large and quite unexplained. Prof. Ayrton suggested a crucial experiment to determine whether atmospheric electricity is due to an actual distribution in the air, or to induction from the earth's surface.

The report of the Ben Nevis Observatory for 1894 was presented. The mean hourly velocity of the wind at the top of the mountain, and the mean rainband, are included in the report for the first time. Dr. Buchan and Mr. Omond have made progress in collating the simultaneous records made at Fort William and the summit; the differences between them are to be examined especially with respect to their bearing on coming storms. Even at this stage the results indicate that the present theory of cyclones requires great modification.

The first part of Monday's sitting was devoted to a discussion on the nature of combination tones. Prof. Rücker gave an admirable account of the history of the subject, pointing out that Helmholtz originated both the theory that they are objective, and that which supposes them subjective. He reviewed the theories of Prior and others, according to which summation and difference tones are explained as beat tones of various kinds; and he called attention to Helmholtz's proof that an asymmetrical elastic body, such as the disc of a microphone or the drumskin of the ear, would resound to the difference tone between two notes. Prof. S. P. Thompson regretted that in his historical survey Prof. Riicker did not refer to his own work. He read communications from König and Hermann, defining their views. König distinguishes between beat tones, which can be resonated, and difference tones, to which the resonator does not respond; the latter are subjective. Hermann objects to Helmholtz's theory that it is inadequate to account for the loudness of the combinational tones. Prof. Thompson mentioned experiments to show that difference tones may be obtained by sending one sound to each ear, and in other cases where the drumskin does not receive the sounds. He described also the effect of periodically intermitting a single tone, or of suddenly and periodically changing its phase, in both of which cases a tone is heard the pitch of which is the frequency of phase-change or intermittence.

Prof. Everett sought for the cause of combination tones in the air itself, which would be disturbed unsymmetrically by two sounds of finite amplitude. He thought, however, that in the combined effect of two tones, the vibration corresponding to the fundamental Fourier term common to each would be louder than the difference tone, a view in which Lord Kelvin concurred. Dr. Burton pointed out that Prof. Everett's explanation of combination tones would apply also to phase tones and intermittence tones. Dr. G. J. Stoney thought resonance by the mouth-cavity was an important factor in hearing, and in the selection of separate sounds from among a number. There was a general agreement that summation tones have never been heard, and probably do not exist.

Mr. E. H. Griffiths opened a discussion on the desirability of a new Practical Heat Standard. He showed that the use of water as the standard substance in heat measurements had led to great confusion, on account of the various assumptions as to its variation of heat-capacity with temperature. The curves of heat-capacity of water and temperature, used by different experimenters, were exhibited ; according to which the author's results furnished a value about the mean of those of recent observers. Mr. Griffiths suggests as a heat unit, absolute, independent of any one person's results, and convenient in magnitude, the heat energy of 42 million ergs. To interpret it as a water standard he proposes to take it as the thermal capacity of a gramme of water at $10^{\circ} \mathrm{C}$., as measured by the hydrogen thermometer; and he gives a formula to find the heat-capacity at other temperatures than $10^{\circ} \mathrm{C}$. Lord Kelvin said that Prof. Rankine had previously suggested the dynamical specific heat of water as a standard. Mr. W. N. Shaw thought it advisable to make a distinction between the numbers for the absolute thermal capacity and the specific heat of a substance. He believed this would be done most simply by taking the thermal unit as the heat energy of a million ergs; the specific heat of water at $10^{\circ} \mathrm{C}$. would then be unity, and its thermal capacity 42 units. The choice of a thermal unit has been referred to the Electrical Standards Committee.

NO. 352 , VOL. 52$]$
Dr. C. H. Lees gave an account of the method and results of experiments on the thermal conductivity of mixtures of liquids. The method used was that of Christiansen, in which the heat is conducted through the liquid enclosed between two copper discs, and confined by an ebonite ring if necessary. The results show that the conductivity of mixtures of two liquids is less than the value calculated by the ordinary law of mixture, at any rate for water, ethyl alcohol, methyl alcohol and glycerine. Dr. Lees undertook the experiments to verify certain relations suggested by Prof. H. F. Weber between molecular weight, density, specific heat and thermal conductivity.

A paper by Prof. Ramsay and Miss Dorothy Marshall was read by the latter, the subject being a method of comparing heats of evaporation of liquids at their boiling-points. After remarking that the data of heats of evaporation are very scanty and discrepant, Miss Marshall described a method by which two liquids, kept at their boiling points by jackets of their vapour surrounding them, are boiled by means of equal bare platinum wires heated by an electric current. A comparison of the amounts of the liquids evaporated in a given time gives the ratio of heats of evaporation. For absolute values a special determination was made on benzene by Mr. Griffiths and Miss Marshall. Alcohol was carefully compared with benzene, and all other liquids were then compared with alcohol. Water was very erratic in its behaviour, probably because of its greater electric conductivity.

Mr. G. U. Yule exhibited a harmonic analyser.

At the meeting on Tuesday, Lord Kelvin described the results of experiments for the electrification and diselectrification of air and other gases, made by Messrs. Maclean and Galt, and himself. In the earlier experiments the air inside a metal can was electrified by points, the can being put to earth ; on insulating the can and blowing out the air, the charge acquired by the can was equal and opposite to that of the air. Electrification of air and other gases in gas-holders over water, by points and flames, was also tried, greater electric densities being thus obtained than by the previous method. The maximum effects were $\mathrm{I}^{-} 5 \times \mathrm{IO}^{-4}$ electrostatic units per c.c. for air, and $2.2 \times \mathrm{IO}^{-4}$ for $\mathrm{CO}_{2}$. The gases were diselectrified by "filtering" them through metal tubes containing conducting wire gauze and cotton wool. Very little electrifying effect was found when uncharged air passed through a platinum tube $100 \mathrm{~cm}$. long and $\mathrm{I} \mathrm{mm}$. diameter, until the tube was made red-hot, in which case the air acquired a strong positive charge. Prof. Oliver Lodge suggested the use of a filter consisting of a metal tube, highly polished inside and illuminated by an electric beam shining into its interior. Lord Kelvin said that in all Hertz's or Elster and Geitel's experiments on diselectrification by light, the charge of the air round the illuminated body should be examined.

Prof. Rücker made a communication on vertical (earth-air) electric currents. At the meeting of the Association last year, Dr. Adolph Schmidt accounted for a portion of the earth's magnetism by assuming electric currrents to pass vertically between earth and air. Such currents would be shown by the non-vanishing of the line-integral of magnetic force when taken round a closed circuit on the earth's surface. The matter was tested in this way by Messrs. Kay and Whalley, using four independent circuits, three in Great Britain and one in Ireland, and obtaining the data of magnetic force from the surveys of I 886 and I89I. The results do not decide the general question, but they show that in the United Kingdom the upward current has certainly not more than one-tenth of the value required in Dr. Schmidt's theory. Lord Kelvin calculated that the current assumed by Dr. Schmidt $\left(\mathrm{O}^{\cdot} \mathrm{I}\right.$ ampere per square kilometre of surface) amounts to a removal of the fine-weather charge of the air near the earth 36 times per second. Dr. Rijchevorsel said he understood that magnetic observations were about to be made in Switzerland, which would furnish data for similar calculations there.

Mrs. Ayrton made a communication on the connection between potential difference, current and length of arc, in the electric arc. The results of carefully-performed experiments, verified also by recalculation from the data of other observers, show that the following relations hold :-(1) For constant length of arc the power (number of watts used in the arc) is a linear function of the current; (2) for constant currents the power is a linear function of the length of arc ; (3) for constant length of arc the curve of potential difference and current is a rectangular hyperbola. All these laws are included in the President's statement that the surface with potential difference, current and arc length as coordinates, is a hyperbolic paraboloid. 
Prof. Ayrton read a paper by Mr. Mather and himself, in which arguments were advanced against the existence of a back electromotive force in the electric arc. The authors describe a method of measuring the true resistance of the arc, namely the ratio of a small increase of potential difference to the corresponding increase in the current; this, of course, is a negative quantity. The same authors described a magnetic field-tester, an application of the ordinary exploring coil and ballistic galvanometer method, with a spiral spring to effect rapid rotation of the exploring coil, and a modified D'Arsonval galvanometer with shuttle-wound coil capable of rotating through several turns without losing the proportionality of angular displacement and restoring force.

The velocity of light in vacuum tubes conveying an electric discharge formed the subject of a paper by Messrs. Edser and Starling. Vacuum tubes were placed in the path of the two beams of a Fizeau interference apparatus, and the position of the bands observed. No appreciable shift of the bands was obtained either by setting up an induction-coil discharge, or by the discharge of ten gallon jars through the tubes when placed in series with a piece of wet string. The discharge in the latter case lasted one-thirtieth of a second, and the authors show that a disturbance of the bands of so long duration would have been observed.

Mr. F. G. Baily read a paper on hysteresis of iron in an alternating magnetic field, in which he showed that the hysteresis of iron increases with the field up to a maximum value, in accordance with Ewing's theory. The experiments were made by the isthmus method, using a small laminated armature consisting of thin discs of charcoal iron ; the most intense magnetic field used was 22,000 C.G.S. units, and the hysteresis was measured by the rise of temperature of the armature.

On Wednesday, Dr. Gladstone and Mr. W. Hibbert made a communication on the change of molecular refraction in salts or acids dissolved in water. The molecular refraction of a substance is altered when the substance changes its state, and a further slight alteration takes place on diluting its solution ; the authors have obtained some evidence of a close connection between these changes and the variations of electric conductivity of the substance and its solutions. Such a connection would have an important bearing on the theory of solution.

The report of the Electrical Standards Committee was read. The Committee hope during the year to institute a comparison between the British and German standards of resistance, and have procured coils for this purpose, which have already been tested at the Reichsanstalt. The Committee, recognising the need for practical units of magnetic field and magnetic potential, recommend for tentative adoption (I) a unit equal to $\mathrm{IO}^{8} \mathrm{C}$.G.S. lines, to be called a weber, (2) the C.G.S. unit of magnetic potential, to be called a sauss. They also recommend that the termination ance be used in describing the properties of a piece of matter, e.s. the resistance of a copper wire, and the termination ivity or ility for the specific properties of the material, e.g. the resistivity of copper would mean the resistance of a centimetre cube of it. Prof. Oliver Lodge explained, and advocated the use of, the proposed units. Prof. S. P. Thompson, while agreeing with the Committee as to the desirability of having units of magnetic field and magnetic potential, thought the choice of their names should be left with the practical men who use them. He believed the proposed weher was too large, and advocated the retention of the C.G.S. "line," using the kilo- and mega- for its multiples; further, he did not see any necessity for abandoning the ampere-turn in order to replace it by the gatess. Prof. Thompson pointed out a more formidable objection, namely, that the American Institute of Electrical Engineers have attached the name weber to a different unit, and have suggested the name gilbert for the gauss. Several members continued the discussion, and Prof. Perry expressed his opinion that the question of names ought to be settled by a general congress.

Two pieces of apparatus for tracing the form of the wave of potential in an alternate current circuit were exhibited and described, the one by Messrs. Barr, Burnie and Rodgers, the other by Prof. Ayrton and Mr. Mather.

Mr. E. H. Griffiths exhibited the apparatus designed for the calibration of high-temperature thermometers at Kew Observatory, and described it. A Callendar and Griffiths platinum thermometer is enclosed in a glass or porcelain tube, and can be inmersed, along with the thermometer to be calibrated, in a bath of molten metal or sulphur vapour, according to the temperatures required. Its resistance is measured by a Wheatstone bridge, the coils of which are enclosed in a copper box, five sides of which are immersed in a water-bath of constant temperature, while the top is surmounted by a case similar to that of a chemical balance. The coils of the bridge are of platinumsilver, wound double, and are not embedded in paraffin, the object being to allow them to assume the temperature of the box and surrounding water as quickly as possible.

A vote of thanks to the Chairman and Secretaries terminated the proceedings.

\section{CHEMISTRY AT THE BRITISH ASSOCIATION.}

WITH the exception of Prof. Runge's announcement of the undoubtedly compound nature of helium, few of the communications laid before Section B at Ipswich are likely to awaken great interest outside chemical circles. The discussions, however, which are now a recognised feature of these meetings, were especially successful, and it is not too much to hope that the joint meeting with the newly-formed Botanical Section may be the means, if only indirectly, of bringing about results of great importance to the agricultural community.

Following the President's valuable address, Sir Henry Roscoe and Dr. A. Harden communicated to the Section an interesting discovery in historical chemistry. It has been generally assumed that Dalton arrived at the idea of atoms with definite weights from a consideration of the proportions in which certain elements combined. From the examination of a number of manuscript volumes of Dalton's own laboratory notes, which they have recently discovered in the library of the Manchester Literary and Philosophical Society, Sir Henry Roscoe and Dr. Harden conclude that Dalton worked out his theory solely from physical considerations as to the constitution of gases. His mind being saturated with Newton's ideas concerning atoms, it was from these that his own atomic theory was developed.

Later on, quoting not only his own results but those of other chemists, he seems to have been led to the law of multiple proportions as the only conceivable mode of combination between atoms. Extracts were given from his notes showing that certain numbers, usually quoted as having led him to his atomic theory, e.g. the analyses of marsh gas and olefiant gas, were only inserted in his tables some time after the publication of his ideas.

Prof. Armstrong said it was satisfactory to learn that Dalion had really arrived at his conclusions from truly philosophical considerations, without reference to the very crude numbers, usually quoted as sufficient basis for the laws that he worked out.

The report of the Committee on the teaching of science in elementary schools was read by Dr. J. H. Gladstone. During past years there has been an increase in the number of subjects taught, and in the number of pupils receiving instruction. The alteration in the system of inspection will have an especially useful effect in the teaching of science. The question of the training of teachers is discussed in the report. A course for mistresses on domestic science, dealing as far as possible with the nature of the processes and materials employed in the household, has been found successful. The great obstacles to good science teaching at the present time in elementary schools are: (I) Large classes; (2) multitude of subjects; (3) in sufficiency of the training course for teachers in science subjects; (4) effects of the old science and art system, which is clearly fa too formal, and pays far too little attention to ordinary requirements.

The courses on elementary physics and chemistry, and the science of common things are found to be more attractive than pure chemistry.

Other subjects dealt with in the report are school visits to museums; the right method of giving object lessons ; and the teaching of the metric system. Finally it is suggested as a question worth consideration, whether the recognised school age should not be raised from thirteen to fourteen.

In the discussion which followed the reading of the report, the relation of County Councils to elementary schools was debated, and it was contended that these are helped indirectly by the Councils providing facilities for the training of teachers.

Mr. G. J. Fowler read a paper on the action of nitric oxide on certain salts, by H. A. Auden and G. J. Fowler, in which the action of nitric oxide on different salts at various tempera- 